\title{
Image Choice to Represent the Self in Different Online Environments
}

\author{
Monica Whitty ${ }^{1}$, James Doodson ${ }^{1}$, Sadie Creese ${ }^{2}$, and Duncan Hodges ${ }^{2}$ \\ ${ }^{1}$ Department of Media and Communications, University of Leicester, UK \\ \{mw229,j.t.doodson\}@le.ac.uk \\ ${ }^{2}$ Cyber Security Centre, Department of Computer Science, University of Oxford, UK \\ \{sadie.creese, duncan.hodges\}@cs.ox.ac.uk
}

\begin{abstract}
This paper draws from 'impression management theory' to examine the choices individuals make to visually represent themselves on Facebook and Twitter. We interviewed 20 participants about their image choice and the sorts of inferences others make about their identity. Participants were asked whether they believed their image influenced the types of people who connect with them, and whether their pictorial representation affected the topics and type of communication they have with other people. Contrary to previous research on online impression management, we found that few individuals were motivated to create a specific impression by playing with different images and instead individuals were motivated to appear genuine and authentic. Only a few desired hiding behind an avatar in order to feel freer to self-disclose. We found that Facebook and Twitter were perceived as very different spaces with different affordances and that these perceived affordances influenced participants' choice in image.
\end{abstract}

Keywords: social identity and presence, computer mediated communication, avatars, impression management, online pictorial representations, online identity.

\section{Introduction}

Ever since the beginnings of the Internet, scholars have been interested in how the self is constructed in cyberspace. They have questioned whether we are the same person online, whether we can escape our 'real identity' or whether we can 'experiment' with new identities (e.g., [1-2]). Some scholars argued that the anonymity of the Internet afforded individuals with opportunities to self-disclose more intimate information about themselves (e.g., [3-4]). These questions were asked when people were 'visually anonymous' - but are the same questions relevant to ask about online spaces where individuals are able to pictorially represent themselves (e.g., Facebook, online dating sites)? Do individuals 'play' with constructions of their identities through their choice of images and does their choice of pictorial representation allow them to feel freer to express themselves? In contrast, does the presentation of visual information about someone restrict the amount of information individuals feel comfortable disclosing? Moreover, given the degree of disclosure about self online, there are concerns around 
whether the use of online media can result in exposure to risks of identity and online persona theft [5].

With many online sites (e.g., chat rooms, social networking sites, online dating profiles, and so forth), the initial information individuals are presented with is a visual image chosen to represent the person behind the profile. This paper draws from 'impression management theory' (e.g., [6-7]) to examine the choices individuals make to visually represent themselves on a variety of online sites. In particular, we focus on two different types of social networking sites: Facebook and Twitter.

Goffman [6] developed his impression management theory by examining verbal and non-verbal communication. According to Goffman, individuals overcommunicate gestures that reinforce the desired self and under-communicate gestures that detract from the desired self. Impressions of self are therefore understood to be managed. Goffman described the self as both a 'performer' and a 'character', and contended that the 'self-as-performer' is not merely a social product, but also has a basic motivational core. In contrast, the 'self-as-character' represents an individual's unique humanity. It is this part of the self which is a social product; that is, preformed outwardly in social life. The 'self-as-character' is one's inner self. Goffman believed that individuals need to present themselves as an acceptable person to others. $\mathrm{He}$ stated that "the impressions that the others give tend to be treated as claims and promises they have implicitly made, and claims and promises tend to have a moral character" $[6$, p. 21]. He argued that individuals can be strategic in their impression formation.

Researchers have applied Goffman's theory to online presentations of self. Miller [8] claims that although depth and richness of self-presentation might not seem immediately apparent online, nonetheless "the problem of establishing and maintaining an acceptable self-remains, and there is a range of expressive resources available for this end'. Whitty [9] has applied Goffman's theory to online dating profiles, and has examined the types of profiles which lead to more success.

Leary and Kowalski [7] have extended and modified Goffman's work on impression management. According to these theorists, impression management involves two components: impression motivation (i.e., being motivated to control how others see them) and impression construction (i.e., deciding how they will go about creating the desired impression). Leary and Kowalski argue that people often monitor how they impact on others and attempt to gauge the sorts of impressions they make. Often individuals do not attempt to create a particular impression but instead attempt to maintain their 'public' persona. At other times, however, individuals are highly motivated to create a particular impression. When individuals are motivated to create a certain impression they may alter their behaviours in order to manipulate how others see them. Leary and Kowalski [6] state that their "model accounts not only for why people are concerned with others' impressions of them in a particular social setting, but also for why people adopt one impression management tactic rather than another" (p.36).

The Internet is especially interesting to examine with regards to the topic of impression management given that it has been argued that the Internet affords individuals greater opportunities to create and manage impressions (e.g., [10-11]). This 
affordance, according to some, promotes greater self-disclosures compared with faceto-face environments [4]. It has been argued that this has been made possible because people are visually anonymous online [4]. In addition, others, such as Walther, have argued that the Internet affords greater opportunities for impression management given that many spaces are asynchronous and individuals are able to allocate more cognitive resources to the message composition than they would in face-to-face environments.

The above theories were developed to explain individuals who are visually anonymous and so we know little about impression formation when people are visually present online. Individuals can still be strategic in how they elect to represent themselves visually and so impression management theory may still be very relevant in its application to understanding how people choose to present themselves online. More recently, Nowak [12] has found that the icons individuals select to represent themselves when they use Instant Messaging reflected either physical or psychological characteristics or both.

In this study, we were interested in the choices people make with the initial image they choose for others to view when they encounter their online profile. We focused on Facebook and Twitter images. We choose these two social networking sites given that they serve different social purposes. Specifically, Facebook is more privately oriented with a focus on maintaining connections with existing friendship group [1314]. Conversely, Twitter is more publically oriented with the potential for a different type of audience [15-17]. In particular, we were interested in whether participants chose a photograph of themselves or an avatar and what impression they hoped to achieve from their selection (if any). Drawing from impression management theory, we sought to understand whether individuals were motivated to create a certain impression and how they went about doing this with visual images. Furthermore, we asked participants whether they believed their image choice afforded them opportunities for different types of self-disclosures (e.g., feeling more free to disclose more intimate aspects about themselves) or whether, in fact, these choices inhibited or restricted their self-disclosures.

\section{Method}

The study employed a grounded theory approach [18] which was chosen because the research on this topic area is scant and there is little available theory to draw upon or develop. Grounded theory is an inductive, theory discovery methodology that allows the researcher to develop theory, while at the same time, grounding the theory in data collected in empirical research. It allows a researcher to listen to the data without necessarily imposing preconceived ideas on the data; however, it does not mean that previous theories cannot be brought to light in the analysis [18].

\subsection{Materials}

Given the exploratory nature of our study we created a semi-structured interview schedule for this study. While the basic structure of the interview was adhered to for each 
participant, because of the unique experience each participant had with the online platforms, each participant did not receive the exact same interview schedule. Participants were asked to describe their Facebook and Twitter visual representations (e.g., photograph or avatar) as well as any of their other pictorial representations used on other online applications (e.g., dating and gaming sites, instant messenger, and VoIP).

For each visual representation, participants were asked how they came about choosing their image and whether they felt their choice was in line with the norms of that particular online environment. Participants were then asked whether their image choice expressed anything about themselves or their personality, and the sorts of inferences others might make about their identity given their choice of image. They were then asked whether they believed their avatar influenced the types of people who connect with them in an online environment, and whether their avatar affected the topics and type of communication they have with other people.

\subsection{Procedure}

Prior to commencement of the study, ethical clearance was gained from the University's Ethics Committee. During January 2014, we commissioned Qualtrics to recruit participants from their online panel. Participants were required to have both a Facebook and a Twitter account to allow comparisons of the avatars across the two different spaces. Facebook and Twitter were chosen due to their popularity and the differences between how the two social networks are used (as discussed earlier) Participants were also required to reside in the UK to facilitate the organisation of interviews.

Participants were first required to complete an online survey and from this set of individuals, 20 participants were interviewed for the study reported in this paper. Overall, 1,223 individuals began our initial online survey which asked questions about Internet usage, image choice across a number of online platforms and psychological characteristics. Of these, 209 individuals completed the survey in full and indicated their data could be used for analysis.

Participants for this interview study were recruited from the pool of participants who completed the original questionnaire. In the earlier study, 185 individuals indicated a willingness to take part in the follow-up interview. Each of these participants was contacted about their availability for an interview, and seventy-seven participants responded (41.6\% response rate). Of these 20 were interviewed for this study.

Interviews were conducted over VoIP (Skype in this instance, using the video option), which took approximately 20-40 minutes. Video was chosen given that it afforded a closer face-to-face experience, which is considered more effective at developing a rapport and trust between the interviewer and interviewee than other types of online interviews [19].

\subsection{Participants}

Twenty participants were recruited (10 male, 10 female), each residing in the UK. Participants were aged from 23 to 56 years, with a mean of 36 years $(\mathrm{SD}=10.8$ years). Male participants were aged from 23 to 52 years with a mean of 39 years (SD 
$=8.8$ years). Female participants were aged from 23 to 56 years with a mean of 33 years $(\mathrm{SD}=12.3$ years $)$.

Table 1. Break down of demographics and types of image

\begin{tabular}{|c|c|c|c|c|}
\hline & Age & Sex & Facebook profile image & Twitter profile image \\
\hline 1 & 32 & $\mathrm{~F}$ & Photograph of themselves alone & Photograph of an animal (dog) \\
\hline 2 & 45 & M & $\begin{array}{l}\text { Photograph of a male-female couple, } \\
\text { including participant }\end{array}$ & Photograph of themselves alone \\
\hline 3 & 47 & M & Photograph of themselves alone & $\begin{array}{l}\text { Photograph of themselves alone (did } \\
\text { not match FB) }\end{array}$ \\
\hline 4 & 23 & M & $\begin{array}{l}\text { Photograph with a male-female } \\
\text { couple, including participant }\end{array}$ & Cartoon figure (anime figure) \\
\hline 5 & 50 & M & $\begin{array}{l}\text { Photograph of natural scene (trees } \\
\text { and river) }\end{array}$ & Photograph of themselves alone \\
\hline 6 & 26 & $\mathrm{~F}$ & Photograph of themselves alone & $\begin{array}{l}\text { Photograph of themselves alone (did } \\
\text { not match FB). }\end{array}$ \\
\hline 7 & 36 & M & Photograph of themselves alone & $\begin{array}{l}\text { Photograph of themselves alone, with } \\
\text { a text caption (did not match FB). }\end{array}$ \\
\hline 8 & 56 & M & Photograph of themselves alone & Identical to FB \\
\hline 9 & 23 & $\mathrm{~F}$ & Photograph of themselves alone & Identical to FB \\
\hline 10 & 52 & $\mathrm{~F}$ & Themselves alone & $\begin{array}{l}\text { Photograph of themselves alone (did } \\
\text { not match FB). }\end{array}$ \\
\hline 11 & 36 & $\mathrm{~F}$ & Photograph of their legs & Identical to FB photograph \\
\hline 12 & 24 & M & $\begin{array}{l}\text { Photograph of themselves alone } \\
\text { overlaid with text and logo }\end{array}$ & Identical to FB photograph \\
\hline 13 & 27 & $\mathrm{~F}$ & Photograph of themselves alone & Cartoon figure (anime figure) \\
\hline 14 & 26 & M & Photograph of themselves alone & Default image (Twitter egg) \\
\hline 15 & 51 & M & Photograph of rugby ball & Photograph of rugby player \\
\hline 16 & 34 & $\mathrm{~F}$ & Photograph of themselves alone & Photograph of art work \\
\hline 17 & 39 & $\mathrm{~F}$ & Default image (human silhouette) & Default image (Twitter egg) \\
\hline 18 & 24 & $\mathrm{~F}$ & $\begin{array}{l}\text { Photograph of themselves alone with } \\
\text { an animal (cat) }\end{array}$ & Photograph of themselves alone \\
\hline 19 & 32 & M & $\begin{array}{l}\text { Cartoon of two animals from a televi- } \\
\text { sion show }\end{array}$ & Photograph of themselves alone \\
\hline 20 & 37 & $\mathrm{~F}$ & $\begin{array}{l}\text { Image of a cat overlaid with text and } \\
\text { equals sign logo (a common Internet } \\
\text { meme) }\end{array}$ & Identical to FB \\
\hline
\end{tabular}


Participants tended to use Facebook regularly. Most participants used Facebook more than once a day $(n=14)$, three used Facebook daily, two used it 2 to 3 times per week and one used it once a month. Four participants updated their profile picture 2-3 times a day, six updated daily, four more than once a day, four 2 to 3 times a week, two once a week, two 2-3 times a month and two several times a year. Participants used Twitter less often that Facebook. Most participants tended to use Twitter once a year or less $(n=9)$ or several times a year $(n=8)$ and three use Twitter 2-3 times a month. One participant updated their profile picture once a month, five several times a year, thirteen once a year or less, and one had never changed their Twitter image from the default option.

\section{Results and Discussion}

The following section outlines some of the more interesting results that emerged from our analysis. We first draw from Leary and Kowalski's [6] theory of impression management to consider whether individuals were motivated to 'impression manage', and if so how they went about constructing this impression.

\subsection{Managing an Impression}

A few of our participants were highly motivated to create a certain impression for their perceived audiences. If it was a profile photograph of themselves they thought carefully about the impression they were trying to convey (e.g., via the clothes they were wearing, the expressions on their face or who was in the photograph with them). For example, the following participant expressed how he thought carefully about what he was wearing in his profile photographs and the meaning these clothes conveyed:

I think probably that's the thing I like to show is, I don't know, smart dressing or peculiar dressing, like special things. Not bizarre but in a way different from usual. I think the other one I had before I'm just remembering, I was smoking a Churchill cigar and I had Che Guevara so that sort of image looked absolutely different from any other picture that usually I'd see or I was bored about my previous one. So even if I don't smoke the cigar, usually I smoke it twice a year, it's still the picture I want, so the image I wanted to pass to those looking at me...

I think there are differences in the way you dress... well at least in Italy there is a huge difference between people in the way they dress if they have a socialist background rather than a right wing background and so on. So in a way by showing these particular aspects, I am anyway showing being sympathetic with some sort of line... and so on. So yes, probably if I was open to anyone yes, they would probably get an idea what's my political point of view. (Participant 7)

In preference to a profile photograph, others choose an image to create a certain impression. For example, some choose a cartoon, others pictures of their favourite sports team. In the following example, the participant explains how she choose to take a 
photograph of her feet in high heels rather than a profile photograph that would have clearly given away her identity. She used this image on both her Facebook and Twitter profiles:

I have two names, I am Jenny April [pseudonym], and the in-joke is that Jenny wears ridiculous heels and April does very logical things, and the injoke is that Jenny wears these amazing heels and does all these outrageous things. Which is why when I set up the online profiles for Jenny Lawrence, she wears these outrageous heels and does things that involve hanging upside-down in apple trees in hammocks, whereas in reality April has two children and has to go and do all of those things. So it was very much an online persona that we set up, that's why it's slightly off the wall and it's very much an in-joke...

It was a well chosen image, I didn't just grab one off of ... To be fair what I have is thousands of images on my computer, this one was very personal to me and said a lot about me. (Participant 11)

Managing Audiences and Conversations. In some cases the images were chosen in order to generate a specific type of conversation or draw in a specific audience. For example, one participant talked about pet lovers approaching her on twitter because she had used a photograph of a dog, whilst another participant talked about attracting rugby players as he had an interest in rugby in preference to football.

\subsection{Authenticity}

As mentioned in our Introduction, Leary and Kowalski [6] argue that often individuals do not attempt to create a specific impression but rather aim to maintain their public persona. This appeared to be more the case with our particular sample. Rather than attempting to create an impression by playing with different images, most participants felt it was important to appear genuine and authentic. Many stated that in order to do this a photograph of themselves (often a very recent photograph) was necessary. Moreover, this served a second purpose, which was to help people they knew find them to connect with their profile. This is clearly expressed by the following participant:

To me I think it's a simple photo, it shows you as the person. I think if it's in a profile picture you're the profile. People know your face but they're not really interested in looking at a picture of a house or your dog or your car, I think they like to see what you like to look like at present or the past. Because I know some people seem to use old photos 20 years ago, which is great because obviously if you've got an old friend on Facebook you remember them, but if the person knows it's you by the name, why are you trying to be in the past when you're now in the present? It's a nice little picture, I like that that one, the white shirt. That was round the kids' house. (Participant 8)

\subsection{Anonymity}

Earlier research found that many online users enjoyed the anonymity the Internet afforded given that it provided a space for them to feel free to self-disclose. Very few 
of our participants choose or wished to hide behind an image, although there were a couple who enjoyed using an avatar to disguise their true identity in order to express themselves in ways they would not have done had they used a photograph of themselves. This is explained by the following participant:

But just though a conscious sort of thing of "ah, but then they'll know what my face is". If they saw me down the street and they didn't like what I said they could just "oi you're a prick" for something you did on Twitter a long time ago that no one would really remember. Whereas if it wasn't a picture of me then they wouldn't know what I look like so I can just tweet someone and just say oh, you know a celebrity, that "I really enjoyed this show you were on bla bla bla" or "I really dislike the show you were on bla bla bla". The fact that not having a picture of me makes it easier to communicate with people on Twitter...

Well, like I said celebrities mainly. I see something on TV, er, one of the ones that's been getting to me recently is Dancing on Ice...

Watch Dancing on Ice and in the first week, a celebrity pair that I thought did really well went out due to public vote. And I feel that...if I a picture of me...on my Twitter profile, I wouldn't have sent a message that I did. And I sent a message that was...just a little bit rude. (P4).

\subsection{Affordances of the Space}

Participants often perceived Facebook and Twitter as very different spaces, each attracting different audiences to their profile. Facebook was more likely to be perceived as a place to connect with people they knew, including family members (most seemed to use privacy settings to restrict their audience), whilst Twitter was seen as a more public space. This perception appeared to influence the choices of images participants opted to present. Many felt that a recent photograph on Facebook was imperative, while the need for a photograph or authentic image was not as important for many on Twitter. Consistency of images across sites often appeared to be a decision dependent on the perceived audience as well as how the individual decided to use the site. Interestingly, not all individuals used these sites in the same way. For example, one participant pointed out that he believed that Twitter users can be either 'broadcasters' (someone who wishes to write many messages for others to read) or 'receivers' (someone who prefers to read others tweets) or both. Again, this type of perception may well influence users' image choice.

\section{Conclusions}

We began this paper by pointing out that scholars had noted that the Internet has afforded individuals with more freedom to play with identity and hide behind presentations of self in order to enable greater self-disclosures. The model we are developing here suggests this is not the case. Some individuals in our sample appeared to be very 
strategic in their choice of image, in the hope of creating a certain impression or to generate specific conversations. However, in the main, participants choose recent photographs to represent themselves and expressed a wish to be authentic and genuine towards others. This was stronger for Facebook than it was for Twitter and so the type of online space and the affordances this space is perceived to provide needs to be taken into account in any model developed to explain profile image choice.

Our future work will extend this analysis to: identify habits and motivations behind the choices that people make when selecting an avatar, and whether those motivations and habits are influenced by the type of online environment; examine links between personality and choices that people make when selecting an avatar; examine whether the type of online environment influences the extent to which an avatar represents the users physical body and personality; and identify the degree to which any of these choices are influenced by perceptions of online risk. Profile pictures and avatars are both ubiquitous (meaning most online environments include some form of pictorial representation) and easily obtainable by anyone which makes the choice of avatar an interesting security vulnerability. Of course, the vulnerability of identity and personas is something that is well understood in the security community but much less in the non-expert community. Therefore, as concerns around vulnerability begin to gain strength across society we might expect this to impact upon choices surrounding selfdisclosure including graphical representations. The relationship between personality, perceptions of risk, and self-disclosures is a topic that we must return to in the longerterm if we are to better understand how best to support individuals in their own personal management of such risks.

\section{References}

1. Haraway, D.: Simians, cyborgs and women: The reinvention of nature. Free Association Books, London (1991)

2. Turkle, S.: Life on the screen: Identity in the age of the Internet. Weidenfeld \& Nicolson, London (1995)

3. Bargh, J.A., McKenna, K.Y.A., Fitzsimons, G.M.: Can you see the real me? Activation and expression of the "true self" on the Internet. Journal of Social Issues 58, 33-48 (2002)

4. Joinson, A.N.: Knowing me, Knowing you: Reciprocal self-disclosure on the Internet. Cyberpsychology and Behavior 4, 587-591 (2001)

5. Creese, S., Goldsmith, M., Nurse, J.R.C., Phillips, E.: A data-reachability model for elucidating privacy and security risks related to the use of online social networks. In: Proceedings of Trust, Security and Privacy in Computing and Communications (TrustCom), pp. 1124-1131. IEEE, New York (2012)

6. Goffman, E.: The presentation of self in everyday life. Penguin, London (1963)

7. Leary, M.R., Kowalski, R.M.: Impression management: A literature review and twocomponent model. Psychological Bulletin 107, 34-47 (1990)

8. Miller, H.: The presentation of self in electronic life: Goffman on the internet. Embodied Knowledge and Virtual Space (1995), http://ess.ntu.ac.uk/miller/cyberpsych/goffman.htm

9. Whitty, M.T.: Revealing the 'real' me, searching for the 'actual' you: Presentations of self on an Internet dating site. Computers in Human Behavior 24, 1707-1723 (2008) 
10. Walther, J.B.: Selective self-presentation in computer-mediated communication: Hyperpersonal dimensions of technology, language, and cognition. Computers in Human Behavior 23, 2538-2557 (2007)

11. Walther, J.B., Slovacek, C., Tidwell, L.: Is a picture worth a thousand words? Photographic images in long-term and short-term computer-mediated communication. Communication Research 28, 105-134 (2001)

12. Nowak, K.L.: Choosing Buddy Icons that look like me or represent my personality: Using Buddy Icons for social presence. Computers in Human Behavior 29, 1456-1464 (2013)

13. Joinson, A.N.: Looking at, looking up or keeping up with people?: Motives and use of Facebook. In: Proceedings of the SIGCHI Conference on Human Factors in Computing Systems, pp. 1027-1036. ACM, New York (2008)

14. Raacke, J., Bonds-Raacke, J.: MySpace and Facebook: Applying the uses and gratifications theory to exploring friend-networking sites. Cyberpsychology \& Behavior 11, 169-174 (2008)

15. Huberman, B., Romero, D., Wu, F.: Social networks that matter: Twitter under the microscope. First Monday 14 (2008),

http: / / firstmonday.org/article/view/2317/2063

16. Hughes, D.J., Rowe, M., Batey, M., Lee, A.: A tale of two sites: Twitter vs. Facebook and the personality predictors of social media usage. Computers in Human Behavior 28, 561-569 (2012)

17. Marwick, A.E.: I tweet honestly, I tweet passionately: Twitter users, context collapse, and the imagined audience. New Media \& Society 13, 114-133 (2011)

18. Glaser, B., Strauss, A.: The discovery of grounded theory: Strategies for Qualitative Research. Aldine De Gruyther, Chicago (1967)

19. O’Connor, H., Madge, C., Shaw, R., Wellens, J.: Internet-based interviewing. In: Fielding, N.G., Lee, R.M. (eds.) The SAGE Handbook of Online Research Methods, pp. 271-289. SAGE Publications Inc., Los Angeles (2008) 